Article

\title{
Encouraging Pro-Environmental Behaviors Through Children-Based Appeals: A Kin Selection Perspective
}

\author{
Gonzalo Palomo-Vélez *, Jacek Buczny®i] and Mark Van Vugt \\ Department of Experimental and Applied Psychology, Vrije Universiteit Amsterdam, 1081 BT Amsterdam, The \\ Netherlands; j.buczny@vu.nl (J.B.); m.van.vugt@vu.nl (M.V.V.) \\ * Correspondence: g.f.p.v.palomovelez@vu.nl
}

Received: 10 December 2019; Accepted: 15 January 2020; Published: 20 January 2020

\begin{abstract}
Environmental problems are due to the fact of humans prioritizing their narrow personal interests over collective interests. How can pro-environmental behavior be promoted without requiring people to behave in ways that go against their selfish tendencies? Kin selection theory asserts that humans are predisposed to ensure the survival and replication of their genes which they share with their offspring. We hypothesized that appeals to the welfare of their children would foster pro-environmental decision-making through activating a parental care motivation. Four studies examined the impact of messages about the welfare of (potential) children on environmental intentions. Overall, the results show that children-based appeals indirectly fostered ecological intentions through an increased parental care motivation. Furthermore, meta-analyses triangulated these findings by showing that people with children show greater parental care and pro-environmental intentions. These results are discussed in light of the kin selection theory, and its implications for environmental policymaking are addressed.
\end{abstract}

Keywords: pro-environmental intentions; kin selection theory; inclusive fitness theory; children-based appeals

\section{Introduction}

Among the major challenges the world is facing is the problem of global environmental change. Experts estimate that, if nothing is being done, by 2052, the earth temperature is likely to rise by $1.5^{\circ} \mathrm{C}$ above pre-industrial levels [1]. Such an increase in temperature will probably have devastating ecological and social effects, the costs of which will be carried by future generations. Over the past few years, these future generations-our children and grandchildren-have come out in massive numbers to make a stance against climate change and persuade governments and industry to take appropriate action to promote sustainability. For example, on 20 September 2019, more than 4 million schoolchildren participated in demonstrations worldwide to demand political action for a better climate [2]. Are these attempts effective? Are governments and the people who vote for them persuaded by appeals about the welfare of their children and grandchildren? This research examines the effectiveness of children-based appeals in persuading people to behave more sustainably.

One of the main obstacles to sustainable behavioral change is that many environmental problems are social dilemmas [3]. Social dilemmas are known in the social sciences as situations in which people manage conflicts between their immediate personal interests and long-term collective interests [4]. Although claiming extra resources for oneself is the rational thing to do, such selfish actions constitute a problem for the collective in the long term $[5,6]$. In social dilemmas, the common pool is only maintained if individuals show restraint [7]. The classic story of the tragedy of the commons serves as a metaphor for these types of problems [8]. This parable depicts how a small pasture shared by multiple herders is devastated because, despite the fact that every herder wants to maintain suitable 
pasture levels for the survival of their cattle, they each realize that by just adding some more animals to the pasture, they could receive more profit at the expense of their peers; thus, leading the pasture to overexploitation. Although Hardin [8] proposed that the only alternative to avoid devastation of the commons is jointly agreed coercion, exercised through institutions responsible for managing the commons, an evolutionary framework predicts that, in certain circumstances, people can behave in a cooperative and altruistic manner especially if their long-term genetic interests are highlighted [9].

\subsection{Kin Selection Theory}

Studying environmental dilemmas from an evolutionary psychology perspective may give some insights for environmental policymaking [3,10]. Evolutionary perspectives on human decision-making suggest that there are several ways out of the commons tragedy. Studies on human cooperation have emphasized the role of punishment [11], reciprocity [12], and reputation [13,14] in promoting cooperation for the environment. However, a crucial, additional factor to consider is the role of kinship. Hamilton [9] defined inclusive fitness as a mathematical rule which posits that an organism will behave in an altruist fashion if such behavior increases the fitness of others who share the organism's genetic makeup. According to this rule, an actor will be altruistic only if the product of the recipient's benefits derived by the actor's altruist act (B) and the genetic relatedness between the two of them (r) exceeds the cost of behaving in an altruistic manner for the actor (C); the rule thus can be expressed as $r B>C$.

Indirect fitness through relatives is often referred to as kin selection. Kin selection theory asserts that humans are predisposed to ensure the survival and replication of their genes which they share with kin including their children [15]. A child shares $50 \%$ of their genes with a sibling as well as with each biological parent, and children share $25 \%$ with each of their grandparents. Animal behavior studies provide much support for Hamilton's rule [16,17]. As the relatedness within the group varies, individuals cooperate more with those that share more of their genes [18,19]. Psychological research shows that in hypothetical life-and-death situations, people are more likely to help members of their close family, compared to more distant kin [20]. Moreover, because perceptions about genetic relatedness are not error free, people also cooperate more with individuals that they share a physical resemblance with, like facial similarity [21].

\subsection{Can Kin Appeals Save the Environment?}

Following the logic of kin selection, we propose that, in environmental campaigns, a reminder of kinship —an appeal to the welfare of one's kin, especially their biological children-may encourage pro-environmental intentions [10]. Indeed, previous work has shown that in resource dilemmas, a cue of kinship prevents the commons tragedy described by Hardin [8] by promoting collective restraint. Krupp, Debruine, and Barclay [21] reported the results of a public goods game in which participants played against ostensible participants who varied in their degree of facial resemblance with the actual participant. As expected from a kin selection perspective, public good contributions increased as the facial resemblance between group members increased.

Although kin selection theory predicts environmental cooperation among all kinds of close genetic relatives, here, we focused on parents and children specifically. Some lines of research in environmental psychology and environmental demographics are consistent with the idea that people with children care more about the future of the planet. For instance, previous research has shown that people with larger families tend to have more environmental knowledge and more positive attitudes towards environmental quality [22], and that parents, compared to non-parents, are willing to pay more for environmental goods improvement [23]. Also, other work has indicated that married women parenting at least one child are more willing to pay for an environmentally friendly product than women who are not yet mothers [24]. Similarly, Loureiro et al. [25] showed that being female and having children in the household increased the willingness to pay for eco-labeled apples. Furthermore, using hypothetical children-based appeals, Van de Vyver et al. [26] showed reduced engine idling at long wait stops among car drivers. This finding is consistent with recent research on animal conservation showing 
that kinship appeals increase conservation efforts for a fictitious endangered animal, compared to anthropomorphic appeals, where the species was framed as a metaphor of a non-genetically related human [27]. Also, unpublished work by Neufeld et al. [28] has shown that the use of kin-based appeals stressing the welfare of potential children enhances people's self-reported willingness to perform pro-environmental behaviors.

Yet, not all studies have found consistent results on this matter. Fisher et al. [29] found that having one or two children increased the likelihood of recyclable bag use but no other environmentally friendly behaviors. Thomas et al. [30], using longitudinal data representative of the UK population, failed to find evidence that having a newborn increases parents' self-reported environmental attitudes and behavior. Instead, the authors reported that having a newborn led to a small decrease in the frequency of three (out of fourteen) pro-environmental behaviors such as car-sharing and the use of public transport as alternatives to the use of personal automobiles. A potential reason for these inconclusive findings is that certain contextual factors might obscure the effect of children-based appeals on environmental outcomes. As pointed out by several authors (e.g., [26,30]), an increase in family size (e.g., having a newborn) might increase pro-environmental concerns, but at the same time might produce a less environmentally friendly lifestyle temporarily due to the fact of, for instance, financial concerns, safety issues, or time constraints. Indeed, previous research shows that an association between parenthood and being worried about the consequences of climate change emerges only when emotional aspects of the risk are measured but not when parents are just required to conduct cognitive-based estimates of the risk [31]. It is thus important to focus more on the psychological mechanisms involved in environmental decision-making in family relations.

\subsection{Parental Care}

Following the logic of kin selection theory, environmental intentions may be fostered by a parental care motivation which, in turn, may be influenced more distally by the salience of having children. The fundamental motives framework asserts that the pursuit of different fundamental motives (e.g., for protection, parenting, status) leads humans to behave in ways that maximize their survival and reproductive success [32,33]. Parental care motivation activates people's concerns about family members and triggers behavior that is aligned with people's genetic interests. This evolutionary-based framework indicates that certain aspects of the many different situations humans commonly encounter in their daily life act as cues that temporarily activate one or various fundamental motives guiding social behavior [34]. For instance, a crying baby may signal to parents that their offspring is in danger and, therefore, increase their parental care motivation which should then evoke nurturing and protection behavior among parents. Similarly, exposure to cues that indicate that someone is a parent might increase their parental care motivation towards their children, and this may activate greater concerns and intentions to save the environment, thereby saving their genetic future.

In this investigation, we tested, in four separate studies, whether children-based appeals influence people's pro-environmental intentions through increased parental care motivation. As previous evidence on the direct link between children-cues and pro-environmental outcomes is mixed, here, the main focus was on the potential indirect effect of children-based appeals on environmental outcomes through increased parental care motivation. (Recent literature on path analysis and mediation argues that there is no need for a significant relation between the independent and dependent variables to have an indirect effect [35]. Indeed, as long as there is a significant $\mathrm{a} \times \mathrm{b}$ effect, mediation has occurred [36-39]). We explored this effect on two different environmental outcomes: environmental behavioral intentions (e.g., collecting and recycling used paper) and environmental altruistic intentions (e.g., donating money to and volunteering for an environmental charity). We hypothesized that an appeal to the welfare of one's (potential) children increases the motivation for parental care which, in turn, positively predicts environmental behavioral intentions and environmental altruistic intentions. 


\section{Study 1}

\subsection{Materials and Methods}

\subsubsection{Participants}

Four hundred and three participants from the US were recruited through Amazon Mechanical Turk (MTurk). Approximately $50 \%$ of the participants were male, and $48.9 \%$ indicated that they have one or several children. The age range varied from 19 to 78 years old $(M=37.91, S D=11.59)$. (Following Fritz and MacKinnon [40], to achieve 80\% power on $p=0.05$ when testing for an indirect effect with medium-size $\alpha$ and $\beta$ paths, a total sample of 71-74 participants is required. Hence, we are confident that our samples of 403 (Study 1), 302 (Study 2), and 303 (Study 3) participants were enough to test the indirect effect of offspring cues on environmental intentions through the kin care motive. For Study 4, an a priori power analysis was conducted. Also, given that all the studies used MTurk to recruit participants and that manipulations and dependent variables were relatively similar across studies, we used the workers' exclusion function of MTurk to prevent participants that had participated in one of the studies from participating in any of the subsequent ones.)

\subsubsection{Design}

This was a between-subject study with 2 conditions (i.e., control and children-cue condition).

\subsubsection{Measures}

Manipulation check. Participants were asked to answer to what extent the manipulation made them think about their children (i.e., "To what extent did the pictures taken by the Sustainable World Foundation make you think about your children?"; ratings from $1=$ "not at all" to $5=$ "a great deal").

Environmental behavioral intentions. A modified 17 item (ratings from $1=$ "strongly disagree" to 5 = "strongly agree") version of the General Ecological Behaviors scale (GEB) by Kaiser [41] was used. The original GEB contains 38 Likert-type items divided into 7 subscales ( 6 of them representing a wide range of ecological behaviors, whereas the last one covers non-environmental pro-social behaviors; for this study, only the environmental subscales were used which contain items such as "I intend to collect and recycle used paper" and "I intend to contribute financially to environmental organizations"). In this study, our modified version of the GEB showed adequate reliability of measurement $(\alpha=0.83)$.

Environmental altruistic intentions. (1) Donation: Participants were asked whether they would like to donate part of their compensation for participation to the ostensible non-profit green organization, and they had to indicate how much they would like to donate. (2) Register as a volunteer: Participants were asked whether they would like to register as volunteers for the ostensible non-profit green organization ("yes" coded as 1 or "no" as 0 ).

Parental care motive. Following Neel et al. [36], the kin care subscale from the Situational Affordance for Adaptive Problems (SAAP) scale by Brown, Neel, and Sherman [34] was slightly modified to focus on children rather than kin in general. This subscale measures how situation characteristics promote or prevent the achievement of the evolutionary motive related to kin care and, in this case, to parental care. The measure comprises four items $(1=$ "strongly disagree" to $5=$ "strongly agree"); two focused specifically on child care (i.e., "It is important to help my child" and "It is important to take care of my child") and two items with a broader focus that includes children "My relatives (e.g., children, parents, and siblings) need something" and "My relatives (e.g., children, parents, and siblings) need my attention and care". The subscale presented adequate reliability $(\alpha=0.81)$.

Demographics. Participants were also asked about some socio-demographic details such as gender, age, and parental status. (Along with these measures, participants were also asked questions regarding their environmental worldviews. Since our predictions were related to the environmental intentions rather than worldviews, this measure was not used in the present study). 


\subsubsection{Procedure}

After providing consent, all participants were presented with a paragraph asking them to view some pictures about the current state of the environment and what pollution has done to it. Depending on the condition that participants were randomly assigned to, they were asked to consider either the consequences of such environmental changes for the future of their children (children-cue condition, $n=200$ ) or the future of the planet (control condition, $n=203$ ). Then, participants in the control condition were presented with a set of three pictures of different environments being polluted, whereas participants in the children-cue condition viewed the same set of pictures, but these also depicted an adult and a child on them (Supplementary Materials, Annex 1). After being presented with the pictures, participants in both conditions were asked whether they would like to register themselves as volunteers for an ostensible pro-environmental organization "Sustainable World Foundation". Similarly, after that, they were asked whether they would like to donate part of their fee for participating in the study to the same non-profit organization. Finally, all participants were asked to answer a manipulation check, measures related to the parental care motive and their environmental behavioral, and environmental altruistic intentions as well as some demographics. All participants were debriefed at the end of the study regarding the ostensible pro-environmental organization and received their compensation payment even though they had agreed to donate part of it.

\subsection{Results}

\subsubsection{Manipulation Check}

The manipulation had a significant effect on how much participants thought about their children, $F(1,401)=94.92, p<0.001, \eta^{2} p=0.19$. Participants in the children-cue condition $(M=3.26, S D=$ $1.30)$ reported that they thought significantly more about their children than participants in the control condition $(M=2.03, S D=1.22)$.

\subsubsection{Analytical Strategy and Hypotheses Testing}

Our main prediction suggests that children-based appeals will positively influence behavioral and altruistic intentions through an increase in the parental care motive. (An anonymous reviewer suggested to test an alternative theoretical model to evaluate whether parents are more sensitive to children-based manipulations than non-parents. Using moderated mediation models, we tested the interaction between parenthood and children-cue manipulations on all our dependent variables (environmental behavioral intentions, environmental altruistic intentions, and parental care) in each study. The overall results did not provide support for a significant interactive effect between children-cues and parenthood on the pro-environmental dependent variables nor did they for a significant interactive effect between children-cues and parenthood on parental care.) To test this, three mediation analyses (using PROCESS macro; [42]) were conducted. Given the categorical nature of one of the two measures of environmental altruistic intentions (i.e., willingness to volunteer), the mediation model associated with this outcome was carried out based on a logistic regression model in this study as well as in Study 2, Study 3, and Study 4 . Similarly, as the parental care motivation might be influenced by life history variables, such as sex, age, and parenthood status [32,36], all analyses in the present study as well as in the following ones were conducted statistically controlling for these variables. (The results of Studies 1-4 without statistical controls can be found in Annex 5 of the Supplementary Materials. They do not differ from the those presented in the present article).

The results were consistent with our main prediction. The children-cue manipulation positively influenced parental care, $b=0.30, S E=0.07,95 \% \mathrm{CI}(0.16,0.44)$, and the parental care motivation in turn was positively associated with environmental behavioral intentions, $b=0.27, S E=0.05,95 \% \mathrm{CI}$ $(0.17,0.36)$, the percentage of donations, $b=3.47, S E=1.09,95 \% \mathrm{CI}(1.61,5.33)$, and willingness to volunteer, $b=1.22, S E=0.27,95 \% \mathrm{CI}(0.69,1.76)$. Importantly, the results showed positive indirect effects of the children-cue (through parental care) on environmental behavioral intentions, $b=0.08$, $S E$ 
$=0.03,95 \% \mathrm{CI}(0.04,0.14)$ and both environmental altruistic intentions: percentage of donations, $b=$ $1.05, S E=0.37,95 \% \mathrm{CI}(0.47,1.93)$ and willingness to volunteer, $b=0.37, \mathrm{SE}=0.12,95 \% \mathrm{CI}(0.17,0.66)$. Figure 1 presents further details.

Model 1

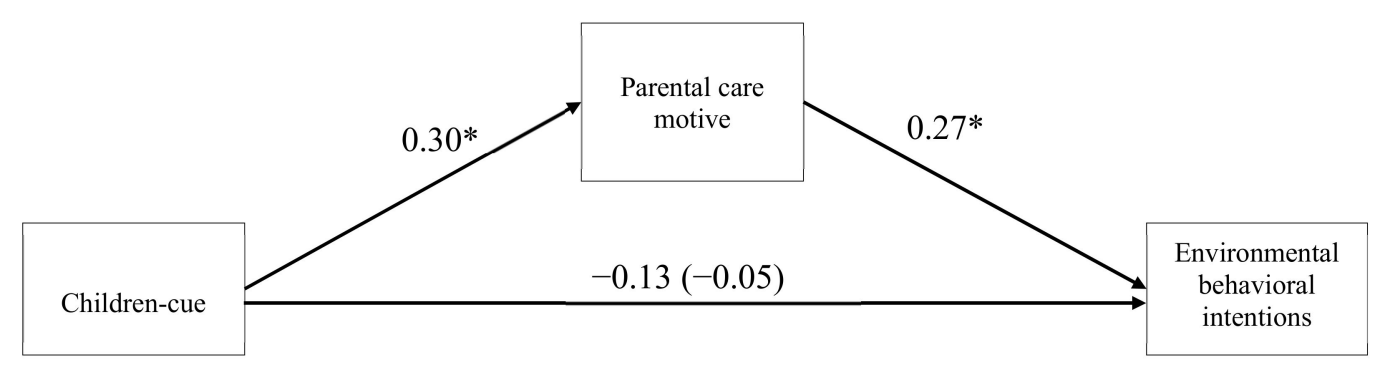

Full model: $F(5,397)=8.37, p<0.001, R^{2}=0.10$.

Model 2

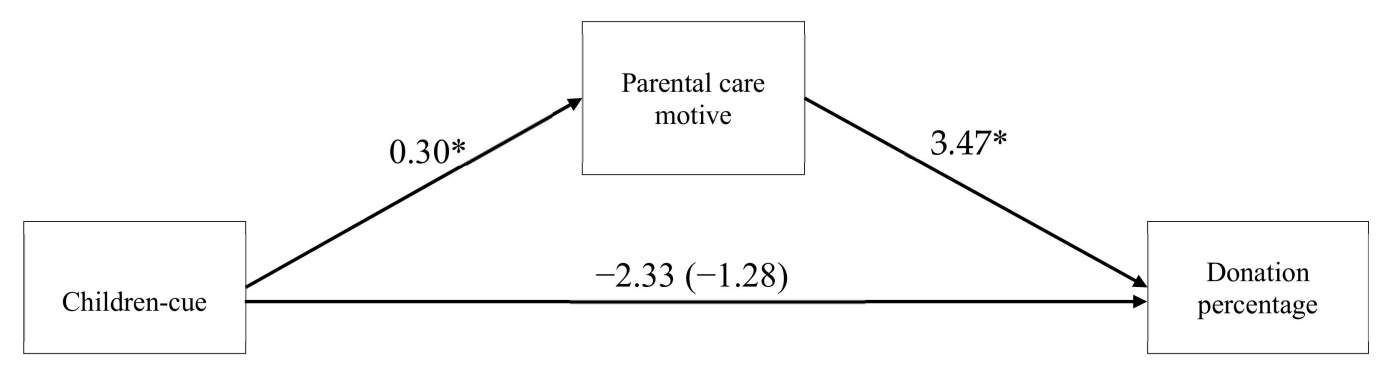

Full model: $F(5,397)=4.28, p<0.001, R^{2}=0.05$.

Model 3

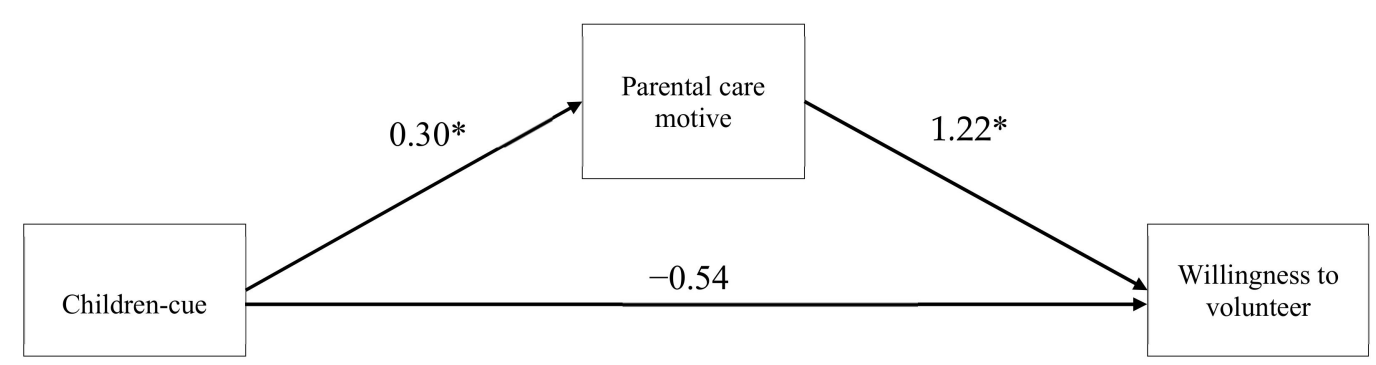

Logistic regression: $-2 \mathrm{LL}=333.44, p<0.001$, Nagelkerke $R^{2}=0.13$.

Figure 1. Effects of the children-cue manipulation on environmental behavioral intentions and environmental altruistic intentions in Study 1. Bootstrapping was fixed to 5000 re-samples and bias corrected. ${ }^{*}=$ CIs do not include zero. Age, sex, and parenthood status were statistically controlled in each model. Manipulation: $0=$ control condition, $1=$ children-cue condition. Total effects in Model 1 and Model 2 are presented between parenthesis next to the direct ones.

\subsection{Discussion}

Based on kin selection theory [15] and the fundamental motives framework [33], we predicted that a children-based appeal would activate the evolved motive to protect one's genetic future and, thus, increase environmental intentions in order to ensure one's children will have a clean environment to live in [10]. Our results supported this idea. Participants whose parental care motive was temporarily activated by the children-cue reported stronger environmental behavioral intentions, tended to donate more, and registered for volunteering more than participants whose parental care motive was not 
activated. Also, our results did not show any direct effect of the children-cue on the dependent variables, giving support to the idea that that other child-related factors (e.g., greater in financial concerns or time constraints associated with having a child) might obscure this effect. In other words, it seems that our results resemble what has been called "indirect-only" mediation [35].

Although Study 1 lent support to our kin selection hypothesis, replication and specification of this effect is still needed. In Study 1, we compared the salience of the children-cue on people's behavioral and altruistic environmental intentions against a more neutral control cue (the fate of the planet). However, according to kin selection theory, the parental care motive should be activated more strongly by the salience of one's biological children rather than by children in general. In other words, if an appeal to someone's children fosters pro-environmental intentions through parental care, an appeal to future generations more generally would not be expected to activate this motive.

Thus, Study 2 had two primary objectives: to investigate whether the results from Study 1 (conceptually) replicate using pro-environmental messages instead of pictures and to specify whether the parental care motive is activated only when one's genetically related children are salient rather than future generations in general. We predicted that (1) the results from Study 1 would conceptually replicate and that (2) an own children-cue would (indirectly) lead to more environmental intentions, donations, and willingness to volunteer when compared to a cue of children more generally.

\section{Study 2}

\subsection{Materials and Methods}

\subsubsection{Participants}

Three hundred and two participants from the US were recruited through MTurk. Approximately $50 \%$ of the participants were male, and $57.3 \%$ indicated that they do not have any children. The age range varied from 21 to 71 years old $(M=36.56, S D=11.09)$.

\subsubsection{Design}

This was a between-subject study with 3 conditions (i.e., control, future-generations, and own-child cue condition).

\subsubsection{Measures}

The measures used were the same as in Study 1, and they showed adequate reliability (environmental behavioral intentions $\alpha=0.84$; parental care motive $\alpha=0.89$ ). For this study, participants were asked to answer a slightly modified manipulation check (i.e., "To what extent did the message from the Sustainable World Foundation make you think about your children?"; ratings from 1 $=$ "not at all" to $5=$ "a great deal").

\subsubsection{Procedure}

After providing consent, participants were presented with a paragraph stating that before starting the actual study, they were to carefully read a pro-environmental message from an ostensible green organization, "Sustainable World Foundation". Three warning messages about the environmental consequences of unsustainable practices of humankind were created for this purpose. Each message contained the same information (stating that "If no new green measures are taken, humanity will be at risk of irreversibly altering the global environment"), design, and image, but they differed in the last sentence. One message did not add any other information (control condition, $n=105$ ), the second one emphasized that the consequences of inaction would be faced by the future generations (future-generations condition, $n=99$ ), and the last one emphasized the consequences of inaction would be faced by the respondent's future children (own-child cue condition, $n=98$ ) (Supplementary Materials, Annex 2). The conditions were randomized. After being exposed to one out of these three 
manipulated pro-environmental messages, participants were asked to write a short letter (200-300 words) directed to either humanity as a whole, future generations, or their own children (depending on what condition they were assigned), in which they explained why they think that it is important to protect the environment. Finally, participants responded to the same measures as in Study 1.

\subsection{Results}

\subsubsection{Manipulation Check}

The manipulation had a significant effect on how much participants thought about their children, $F$ $(2,299)=3.52, p=0.03, \eta^{2} p=0.02$. Bonferroni-corrected comparisons further revealed that participants in the own-child cue condition $(M=3.21, S D=1.32)$ reported that they had thought about their children more than participants in the control condition $(M=2.70, S D=1.45, p=0.03)$. However, participants in the own-child cue condition did not differ significantly to those in the future-generations condition $(M$ $=3.03, S D=1.40, p=1.00)$ and the latter did not differ either to those in the control condition $(p=0.29)$.

\subsubsection{Analytical Strategy and Hypotheses Testing}

Following the analytical strategy used in Study 1, three mediation analyses were conducted to test our hypotheses. We followed Hayes and Preacher's [43] recommendations to conduct mediations with multi-categorical independent variables. When working with multi-categorical independent variables in mediation models, different types of coding can be defined depending on specific comparisons needed. We used sequential coding that compares each group to the following group in one ordinal position higher. The future-generations condition was coded as being the ordinally higher group, followed by the own-child cue condition and the control condition. This type of coding allowed us to test our hypothesis that (1) the results from Study 1 would (conceptually) replicate, and, that even though the manipulation check suggested some overlap between the two experimental conditions, (2) an own-child cue compared to a non-genetically related future-generations cue, would indirectly increase environmental intentions.

The results partially supported our first hypothesis. The own-child cue condition led to higher parental care when compared to the control condition, $b=0.29, S E=0.12,95 \% \mathrm{CI}(0.05,0.52)$, but did not when compared to the future-generations condition, $b=-0.15, S E=0.10,95 \% \mathrm{CI}(-0.35,0.05)$. The parental care motive, in turn, positively predicted environmental behavioral intentions, $b=0.22, S E=$ $0.06,95 \% \mathrm{CI}(0.11,0.33)$. However, parental care did not predict any of the environmental altruistic intentions: percentage of donation, $b=-0.54, S E=1.73,95 \% \mathrm{CI}(-3.94,2.85)$, nor willingness to volunteer, $b=0.51, S E=0.26,95 \% \mathrm{CI}(0.00,1.01)$. Regarding the relative indirect effects of the own-child cue condition on each pro-environmental outcome, our results partially replicated the effects seen in Study 1 . The own-child cue condition, compared to the control condition, showed a positive relative indirect effect on environmental behavioral intentions, $b=0.06, S E=0.03,95 \% \mathrm{CI}(0.02,0.13)$, and on willingness to volunteer, $b=0.14, S E=0.11,95 \% \mathrm{CI}(0.01,0.45)$, but not on percentage of donation, $b=$ $-0.16, S E=0.49,95 \%$ CI $(-1.41,0.67)$.

That said, the results did not provide any support for our second hypothesis. The own-child cue condition did not indirectly influence any of the environmental outcomes when compared to the future-generations condition, the: $b_{\text {environmental behavioral intentions }}=-0.03, S E=0.02,95 \% \mathrm{CI}(-0.09$, $0.01) ; b_{\text {donation percentage }}=0.08, S E=0.28,95 \% \mathrm{CI}(-0.30,1.02) ; b_{\text {willingness to volunteer }}=-0.07, S E=0.08$, $95 \%$ CI $(-0.29,0.02)$. Figure 2 presents further details. 


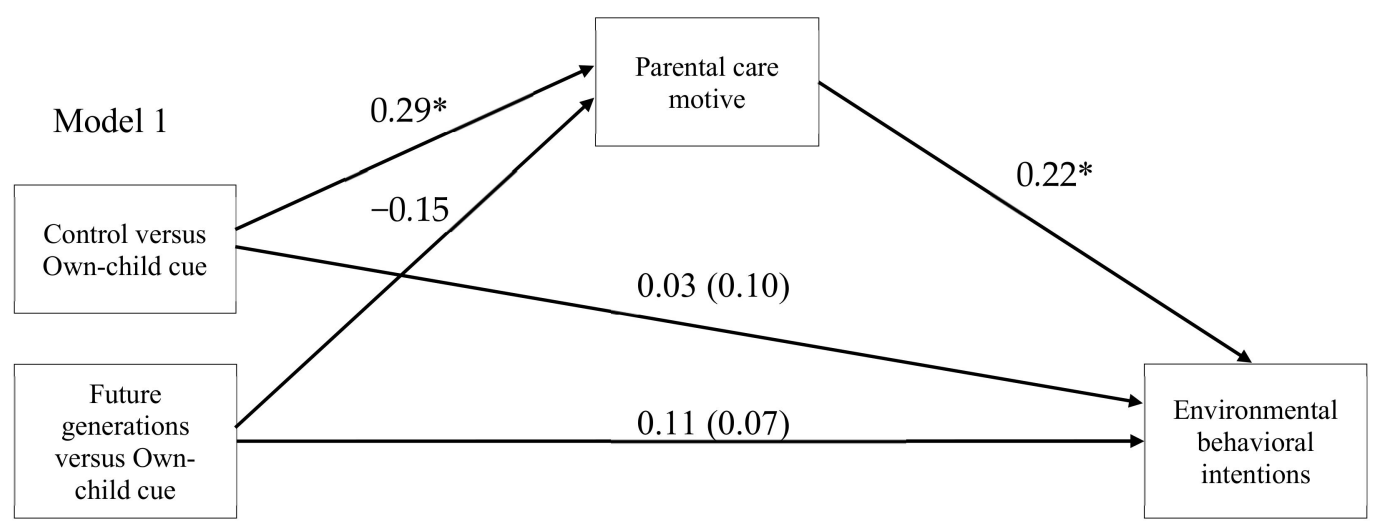

Full model: $F(6,295)=6.35, p<0.001, R^{2}=0.11$.

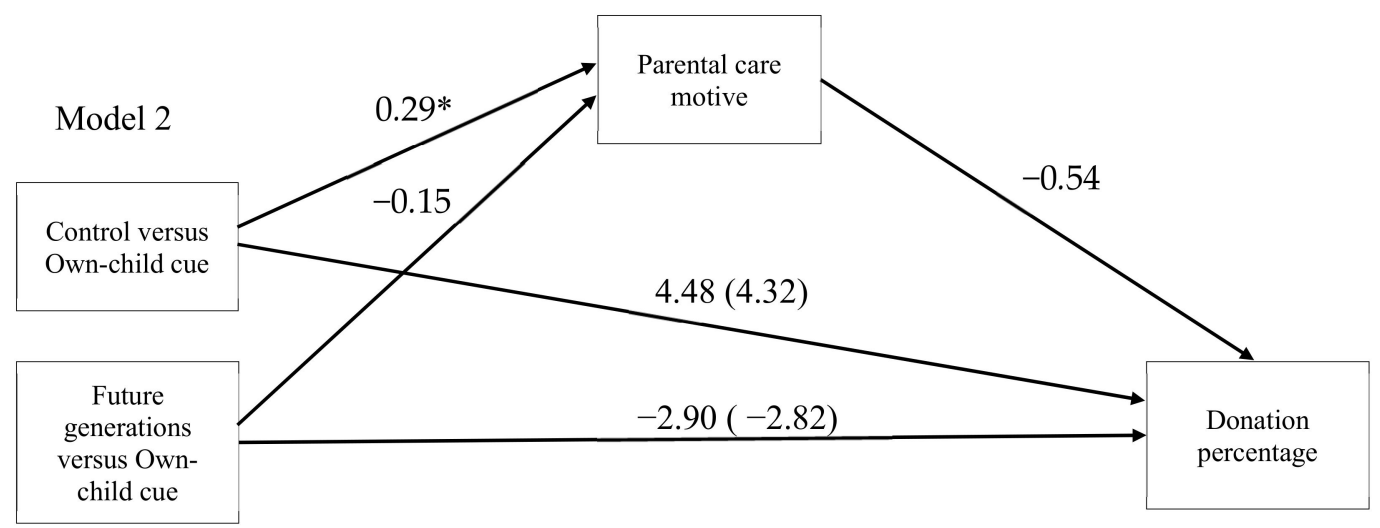

Full model: $F(6,295)=1.28, p=0.26, R^{2}=0.03$.

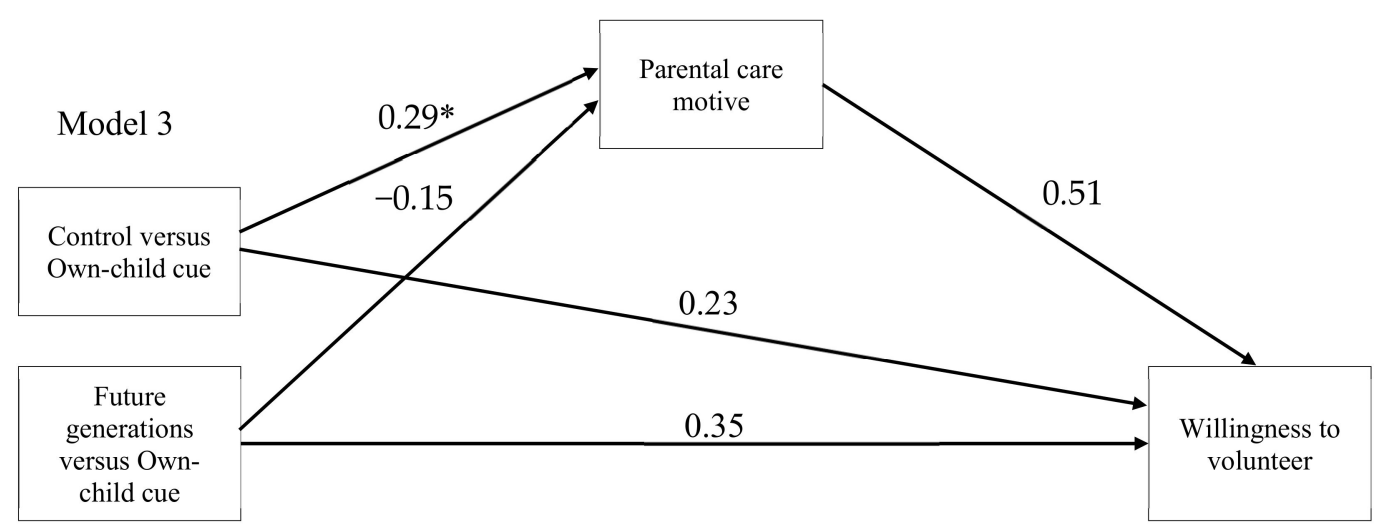

Logistic regression: $-2 \mathrm{LL}=258.51, p=0.01$, Nagelkerke $R^{2}=0.09$.

Figure 2. Effects of the own-child cue manipulation environmental behavioral intentions and environmental altruistic intentions in Study 2. Bootstrapping was fixed to 5000 re-samples and bias corrected; * = CIs do not include zero. Age, sex, and parenthood status were statistically controlled in each model. The future-generations condition was coded as being the ordinally higher group, followed by the own-child cue condition and the control condition. Total effects in Model 1 and Model 2 are presented between parenthesis next to the direct ones.

\subsection{Discussion}

This study tested two main hypotheses. First, that the effects seen in Study 1 would replicate using a different children-based appeal such as an ostensible message within a pro-environmental 
campaign. Second, that the parental care motive would be activated more readily only through the salience of one's biological children as kin selection theory suggests. Regarding the first hypothesis, the results partially replicated the ones we found in Study 1. Although our own-child cue condition, when compared to the control condition, induced positive indirect effects on the environmental behavioral intentions and the willingness to become a volunteer, it did not indirectly increase the percentage of donations.

With respect to the second hypothesis of this study, the results did not support our prediction. The positive indirect effects of the own-child cue manipulation on environmental intentions were only observed when compared with the control condition but not when compared with the future-generations condition. Although there could be multiple potential explanations for this result, one that seems likely is that there might be some overlap between the two experimental manipulations. The concept of future generations does not just involve non-genetically related others only but also an individual's potential own children. Indeed, the manipulation check seems to suggest this with the future generations condition lying somewhere in the middle of the control and the own-child cue condition and sharing some aspects of both treatments. Similarly, another potential explanation might be that the motivational system itself is not entirely accurate in detecting cues. These two ideas are developed further in the general discussion.

Can we be sure that our concern for our kin is driving these effects? According to the inclusive fitness perspective [9], this seems to be the case. However, what if children-based appeals, rather than activating parental care, are making participants value more their own future outcomes? Temporal discounting refers to the tendency to devaluate distant outcomes [44]. From an evolutionary perspective, we are naturally inclined to prioritize immediate needs rather than to focus on distant and uncertain ones $[45,46]$. Such a tendency to discount the future poses an environmental risk. Indeed, literature from inter-generational resource dilemmas has led to the conclusion that greater time delays in expected negative outcomes tend to increase discounting tendencies and undermine pro-environmental efforts [47,48]. Evolutionary psychology, however, assumes that people's discount rates are not fixed, but rather they depend on environmental cues [49]. Thus, it might be the case that a remainder of the future-the salience of potential children — could bring the future forward by reducing people's discount rates. Indeed, Van Gelder et al. [50] showed that imagining oneself in the future (i.e., writing a short letter to their future selves) decreased the tendency to live in the here and now and led to thoughtful considerations of the long-term consequences of one's behavior. Therefore, the increased environmentalism seen in Studies 1 and 2 might have derived from a shift in participants' discount rates rather than from the parental care motivation (as kin selection theory would argue).

Thus, in order to evaluate this temporal discounting alternative explanation, in Study 3, we tested whether a children-cue affects environmental outcomes through an increase in parental care or through a reduced temporal discounting. Additionally, we explored if the results from Kortenkamp and Moore [47], that greater time delays in expected negative environmental outcomes decrease environmental intentions, conceptually replicate.

\section{Study 3}

\subsection{Materials and Methods}

\subsubsection{Participants}

Three hundred and three participants from the US were recruited through MTurk, where $56.8 \%$ of the participants were male, and $58.7 \%$ of participants indicated that they do not have any children. The age range varied from 18 to 68 years old $(M=34.76, S D=10.43)$. 


\subsubsection{Design}

This was a between-subject study with 3 conditions (i.e., close-consequences, delayedconsequences, and a children-cue condition).

\subsubsection{Measures}

Manipulation check. Participants were asked to answer a manipulation check ("To what extent did the scenario you read at the beginning of this survey make you think about your children?", ratings from $1=$ "not at all" to $5=$ "a great deal").

Environmental behavioral intention. Water conservation intentions (WCIs) were measured by a an 8 item scale (ratings from $1=$ "not at all" to $7=$ "very much"). The measure was composed of three items adapted from the water and power conservation dimension of Kaiser's [41] GEB scale: "Would you be willing to take showers rather than baths?", "Would you be willing to wait until having a full load before doing the laundry?", and "Would you be willing to wash your dirty clothes without prewashing?". The next four items were related to a water shortage scenario that participants had to read: "Would you be willing to buy a low-flush toilet?", "Would you be willing to water your plants early in the morning or late at night to reduce evaporation?", and one assessed the participants' overall willingness to conserve water. Reliability analysis indicated an adequate internal consistency $(\alpha=0.83)$.

Environmental altruistic intention. Participants were asked whether they would like to help an ostensible water initiative by sparing $10 \mathrm{~min}$ at the end of the survey and by providing some information regarding their daily water use (response coding: "yes" $=1$, "no" $=0$ ).

Parental care motive. The same measure as in the previous studies was used. Results showed adequate reliability of the measurement $(\alpha=0.92)$.

Temporal discounting. Participants' temporal discounting was assessed using an established measured [51-53] based on the one developed by Kirby et al. [54]. Participants were asked 20 times to choose between receiving an amount of money the day after (swift) or a larger amount in 33 days (delayed). The measure contained items such as "Do you want to receive $\$ 64$ tomorrow OR \$65 in 33 days?" and "Do you want to receive $\$ 42$ tomorrow OR $\$ 47$ in 33 days?", all 20 presented in a counterbalanced order. The amount of money they could get choosing to receive the money the day after varied from $\$ 9$ to $\$ 86$, whereas the amount they could receive in 33 days varied from $\$ 47$ to $\$ 99$. The number of delayed choices was used as a measure of (low) temporal discounting (responses coding: swift $=0$, delayed $=1)$. The results showed adequate internal consistency $(\alpha=0.92)$.

\subsubsection{Procedure}

Participants gave informed consent, and after they agreed to participate, they were asked to read carefully one out of three scenarios related to water shortages occurring in a US state (Supplementary Materials, Annex 3). We used modified versions of one scenario ("Water shortages in Arizona") used by Kortenkamp and Moore [47] to vary the time delays in expected negative environmental outcomes (Supplementary Materials, Annex 3). Participants were asked to imagine the scenario as it was happening to them. The first scenario depicted a call from the city council to reduce water consumption, indicating that if measures are not taken, there is a high likelihood that the freshwater supplies will run out within the next 12 months (close-consequences condition, $n=100$ ). The second scenario depicted the same call for help with water conservation, but instead of one year, this indicated that there was a high chance that freshwater supplies will run out within the next 25 years (delayed-consequences condition, $n=101$ ). The last scenario was identical to the one just described but after indicating that freshwater supplies will run out within a 25 years, it stated that there will be severe consequences for future generations, including one's children (children-cue condition, $n=102)$. Conditions were randomized.

In all conditions, after reading the scenario, participants were presented with an ostensible message from "Watercare Foundation" along with the US Department of Agriculture (USDA) information. 
These messages indicated that, although the scenario they just read was hypothetical, water shortages were real problems for some American states. That was the reason why the USDA and the "Watercare Foundation", as part of a water conservation initiative, were asking US citizens if they would spare $10 \mathrm{~min}$ at the end of the survey to answer a few more questions regarding their water use habits. Next, participants were thanked for their responses and asked to continue with the survey. After that, participants were asked to respond to questions regarding their water conservation intentions, temporal discounting, and the parental care motive as well as a few socio-demographic questions. Finally, participants were debriefed and thanked for their participation in the study.

\subsection{Results}

\subsubsection{Manipulation Check}

The manipulation affected how much participants thought about their (potential) children, $F(2$, $300)=6.96, p=0.001, \eta^{2} p=0.04$. Bonferroni-corrected comparisons showed that participants in the children-cue condition $(M=3.43, S D=1.29)$ indicated that they had thought about their (potential) children more than participants in the close-consequences condition $(M=2.79, S D=1.41, p=0.003)$ and more than participants in the delayed-consequences condition $(M=2.84, S D=1.38, p=0.007)$. These two latter conditions did not differ from each other $(p=1.00)$.

\subsubsection{Analytical Strategy and Hypotheses Testing}

We followed the same analytical strategy used in Study 2 to explore the indirect effects derived from multi-categorical independent variables [43]. To evaluate whether the children-cue influences environmental intentions due to the fact of either an increase in the parental care motive or a reduction in temporal discounting, two mediation analyses, using sequential coding, were performed. The children-cue condition was coded as being the ordinally higher group, followed by the delayed-consequences condition and the close-consequences condition. This coding allowed us to both (1) test whether results from Kortenkamp and Moore [47] conceptually replicate and (2) evaluate whether the children cue increases environmental behavioral intentions through the parental care motive or through temporal discounting.

The results conceptually replicated previous research on time delays on expected negative environmental outcomes. The close-consequences condition, when compared to the delayed-consequences condition, showed a negative direct effect on environmental behavioral intentions, $b=-0.33, S E=0.13,95 \%$ CI $(-0.58,-0.08)$, but not on willingness to volunteer, $b=$ $-0.19, S E=0.31,95 \% \mathrm{CI}(-0.80,0.41)$. This contrast did not affect the parental care measure, $b=-0.15$, $S E=0.13,95 \% \mathrm{CI}(-0.47,0.14)$, nor the temporal discounting one, $b=-0.08, S E=0.36,95 \% \mathrm{CI}(-0.80$, 0.63). In other words, phrasing the expected negative consequences of environmental inaction as being sooner produced stronger water conservation intentions (but not more volunteering) than phrasing them as being distant in the future.

Regarding the precise mechanism behind the effect of the children-based appeal on environmental intentions, the results showed support for the parental care motive instead of temporal discounting. In particular, the children-cue condition, compared to the delayed-consequences condition, positively influenced parental care, $b=0.47, S E=0.15,95 \% \mathrm{CI}(0.19,0.76)$, but not temporal discounting, $b=0.04$, $S E=0.37,95 \% \mathrm{CI}(-0.69,0.76)$. Environmental behavioral intentions, in turn, were positively predicted by both parental care, $b=0.21, S E=0.06,95 \% \mathrm{CI}(0.09,0.33)$, and temporal discounting, $b=0.10, S E=$ $0.02,95 \% \mathrm{CI}(0.05,0.14)$, but none of them predicted willingness to volunteer, $b_{\text {kin care motive }}=-0.02, S E$ $=0.13,95 \% \mathrm{CI}(-0.27,0.22) ; b_{\text {temporal discounting }}=0.06, S E=0.05,95 \% \mathrm{CI}(-0.04,0.15)$.

In terms of relative indirect effects, the results showed a positive relative indirect effect of the children-cue condition compared to the delayed-consequences condition on the environmental behavioral intentions through parental care, $b=0.10, S E=0.04,95 \% \mathrm{CI}(0.04,0.21)$, but not through temporal discounting, $b=0.003, S E=0.04,95 \% \mathrm{CI}(-0.07,0.08)$. Regarding environmental altruistic 
intentions, however, the results did not show any relative indirect effect on willingness to volunteer through none of the mediators: parental care, $b=-0.01, S E=0.06,95 \% \mathrm{CI}(-0.14,0.12)$, nor through temporal discounting $b=0.002, S E=0.04,95 \% \mathrm{CI}(-0.07,0.08)$. For more details see Figure 3 .

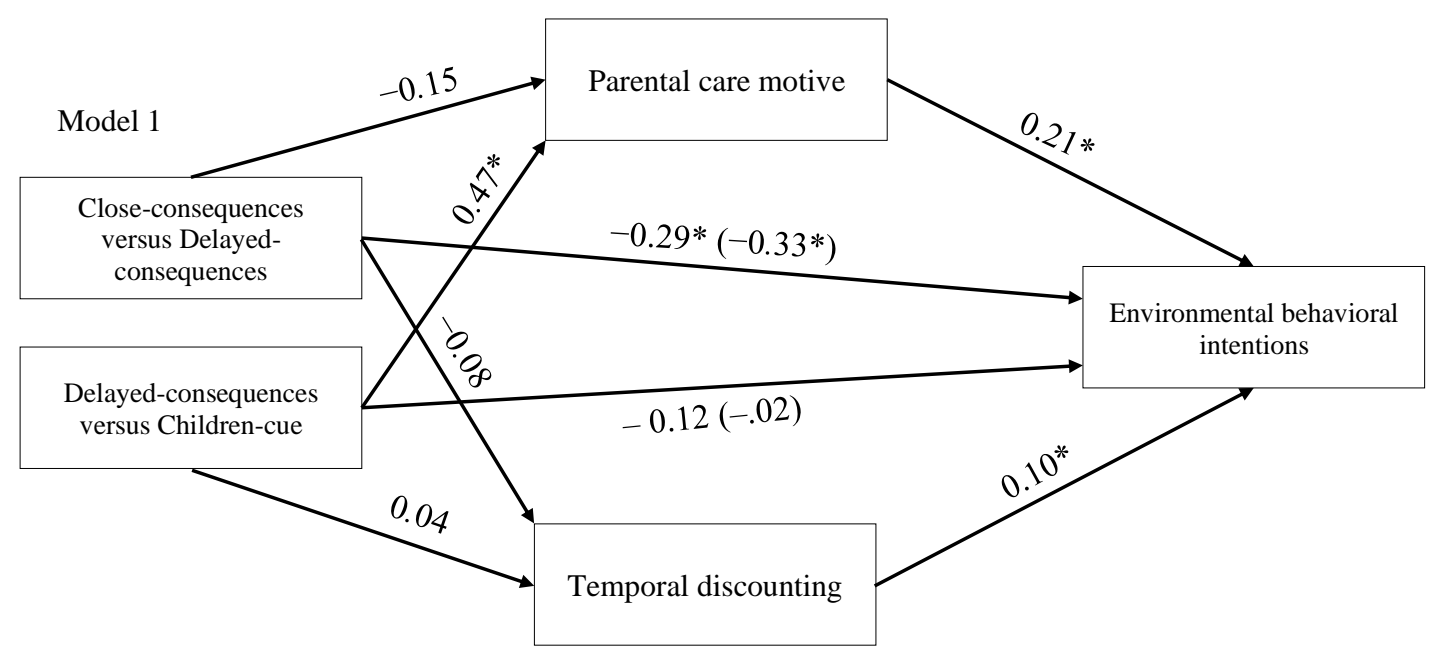

Full model: $F(7,295)=10.42, p<.001, R^{2}=.20$.

Indirect effects of close-consequences versus delayed-consequences:

Through parental care motive: $b=-0.03, S E=.04,95 \%$ CI $[-0.13,0.02]$.

Through temporal discounting: $b=-0.01, S E=.03,95 \%$ CI $[-0.08,0.06]$

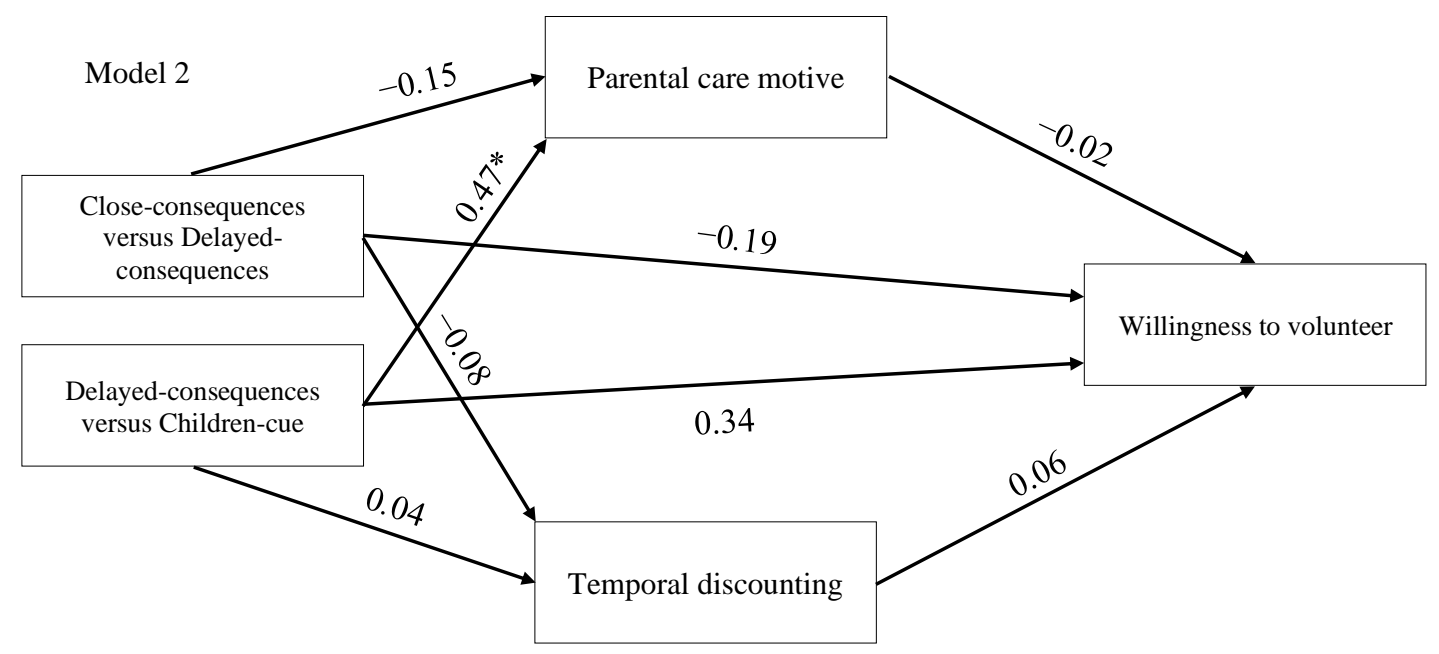

Logistic regression: $-2 \mathrm{LL}=364.74, p=.25$, Nagelkerke $R^{2}=.04$.

Indirect effects of close-consequences versus delayed-consequences:

Through parental care motive: $b=0.003, S E=.02,95 \%$ CI [ $-0.03,0.09]$.

Through temporal discounting: $b=-0.004, S E=.02,95 \%$ CI $[-0.04,0.08]$

Figure 3. Effects of the children-cue manipulation on environmental behavioral intentions and environmental altruistic intentions in Study 3. Bootstrapping was fixed to 5000 re-samples and bias-corrected; ${ }^{*}=$ CIs do not include zero. Age, sex, and parenthood status were statistically controlled in both models. The children-cue condition was coded as being the ordinally higher group, followed by the delayed-consequences condition and the close-consequences condition. Relative total effects in Model 1 are presented between parenthesis next to the relative direct ones. The missing relative indirect effects of the first contrasts in each model are described in the Results section given their main role for the hypothesis. 


\subsection{Discussion}

Based on kin selection theory [15], in this third study, we hypothesized that an appeal to the welfare of one's children would strengthen individuals' environmental intentions to perform water-saving actions through an enhanced parental care motivation. We also tested the alternative hypothesis that an appeal to one's children would reduce temporal discounting rates. Overall, the findings supported the hypothesis derived from kin selection theory over the alternative hypothesis. The findings indicated that the children-cue, indeed, activated participants' parental care motive which, in turn, increased their environmental behavioral intention (water-saving) rather than just preventing them from focusing on their immediate needs. More importantly, this effect was indirectly driven only by parental care and not by temporal discounting.

Our results also conceptually replicated those reported by Kortenkamp and Moore [47]. Specifically, the delayed-consequences condition showed a negatively direct effect on the environmental behavioral intentions (i.e., water-saving) relative to the close-consequences condition. This finding suggests that phrasing the negative environmental consequences as happening sooner is a good strategy to promote environmental behavioral intentions.

\section{Study 4}

In the previous three studies, our results consistently showed that children-cues elicit a parental care motivation which, in turn, indirectly fosters pro-environmental outcomes. However, in these studies, the mediating variable (parental care) was measured rather than manipulated, and, therefore, the indirect effects we observed could be caused by potentially omitted third variables. Because of this, in a pre-registered study, we experimentally manipulated both the independent variable (children-cue: present versus control) and the parental care motivation (type of care: parental versus friendship), applying a concurrent double randomization design [55]. Based on the results of the previous studies, we predicted that (1) participants in the parental care condition would report more environmental behavioral and environmental altruistic intentions than participants whose parental care motive is not activated (i.e., those in the friends care condition). We further predicted that (2) the effect of parental care would be moderated by the presence of the children-cue, in that presenting participants with the children-cue (versus the control cue) would strengthen the positive influence of parental care on environmental behavioral and environmental altruistic intentions. Finally, we also predicted that (3) the presentation order of the two experimental manipulations would not affect the effect of the parental care condition on environmental behavioral, environmental altruistic intentions, and the interactive effect between parental care and the children-cue on the mentioned dependent measures.

\subsection{Materials and Methods}

\subsubsection{Participants}

An a priori power analysis was conducted applying an R script by Perugini et al. [56]. Based on our previous results, we estimated an effect size of 0.025 . Thus, the power analysis using an alpha of 0.05 and a power of 0.80 , suggested a minimum sample size of $N=310$, but to account for exclusions for potential inattentive responses, we aimed to collect at least 350 participants. MTurk was used to recruit an initial sample of three hundred and fifty American participants. However, after a closer examination of the text responses in the data, we noticed that a percentage of participants were probably not fluent in English (i.e., provided nonsensical responses or copied text from internet sources which is not unusual in MTurk samples; [57]). Because of this, we decided to exclude those participants (and those who did not pass the attentional check) and kept iterating the data collection until we reached the aimed minimum sample size (compliance rate was $43.2 \%$ ). Thus, from the valid 310 American participants, $54.2 \%$ were male, and 50.6\% indicated that they do not have any children. The age range varied from 18 to 73 years old $(M=36.65, S D=11.20)$. 


\subsubsection{Design}

This was a 2 (children-cue: present versus control) $\times 2$ (type of care: parental versus friendship) $\times 2$ (manipulation order: children-cue manipulation first versus type of care manipulation first) between-subject design. All study materials and pre-registered hypotheses are available on the OSF: https://osf.io/bjqkd.

\subsubsection{Measures}

We used the same measures as in Study 1 and 2, and they showed adequate reliability (environmental behavioral intentions $\alpha=0.82$; parental care motive $\alpha=0.75$ ). In addition, we also measured participants' emotionality in their text responses by applying text analysis in Linguistic Inquiry and Word Count (LIWC) [58].

\subsubsection{Procedure}

After providing informed consent, participants were told that they would participate in a study about perceptions of life events that consisted of two different tasks. The tasks were presented in random order, but presentation order was recorded to be used as a factor in the data analysis. For the task designed to manipulate the children-cue, we used the same manipulation in Study 1 in which participants were presented with either a set of three pictures depicting a parent and a child observing different polluted environments or with the same three pictures of polluted environments but without the parent and the child in them (Supplementary Materials, Annex 1). After being presented with the pictures, participants were asked to reflect on the consequences of these environmental changes for the future of their children or the future of the planet, depending on the condition. In the task designed to manipulate type of care, participants were told that they would participate in a task about relationship roles and how different types of social situations influence priorities and preferences. We closely followed the procedure used by Li, Haws, and Griskevicius (Study 1, [59]) to induce parental care motivation. This way, half of the participants were randomly assigned to the parental care condition, in which they were asked to imagine being the parent of an infant and put themselves in the role of a parent to answer the questions of the task. After that, they were presented with 10 pictures of babies varying in ethnicity (Supplementary Materials, Annex 4) and asked to select the one that looked most like them. Then, they were requested to give a name to their infant and write down a short but specific paragraph (150-200 words) about what it would be like to be that baby's parent. Participants with the friendship care condition followed a similar procedure but instead of selecting a baby to be his/her parent, they were presented with 10 faces of adults (6 men and 6 women varying in ethnicities selected from an open database of human faces; [60]) and asked to imagine moving to a new place and making new friends. Participants then had to select the adult that looked most like he/she and could be his/her new friend. After that, they were asked to give a name to the new friend and write down a short paragraph (150-200 words) describing what it would be like to be that person's friend. This control condition was designed to evoke emotional closeness but to someone who is not kin.

After completing the two manipulations, participants responded to a manipulation check of parental care motivation (i.e., the measured mediator as recommended by Pirlott and MacKinnon [55]) and answered the dependent measures presented in random order (environmental intentions, willingness to volunteer for an environmental charity, and willingness to donate part of their participation fee to the environmental charity). Finally, participants were requested to respond to an attentional check asking them to indicate how many pictures of polluted environments they saw earlier in the study and to report their age, sex, and whether they have children ("yes" or "no"). After this, participants were debriefed about the real objectives of the study and thanked for their participation. 


\subsection{Results}

\subsubsection{Manipulation Check}

Following Pirlott and MacKinnon [55], first we checked whether our manipulated mediator had the expected effect on the measured mediator. As expected, the type of care manipulation effected parental care, $F(1,308)=12.09, p=0.001, \eta^{2} p=0.04$. Participants in the parental care condition $(M=$ $4.54, S D=0.51)$, scored significantly higher on parental care than participants in the friendship care condition $(M=4.31, S D=0.62)$.

\subsubsection{Analytical Strategy and Hypotheses Testing}

We conducted three moderated moderations (i.e., Model 3; [42]) to test our predictions on the three dependent variables. The children-cue manipulation was used as the independent variable $(X)$, the type of care as the moderator $(\mathrm{W})$, and the manipulation order as the moderator of the moderator $(\mathrm{Y})$. As pre-registered and following Studies 1-3, we statistically controlled for sex, age, and parenthood status. Also, to control for how emotional the text typed by participants was and, thus, exclude the potential alternative explanation that the measured effects could be explained by the emotionality induced by the stimuli, we also statistically controlled for positive and negative emotions in the text [58].

As can be observed in Table 1, the results largely failed to support our hypotheses. Neither the children-cue manipulation nor the type of care manipulation influenced environmental behavioral intentions and donations nor did their interaction.

The results showed an unexpected effect of manipulation order on environmental behavioral intentions, with participants who were presented with the children-cue manipulation first reporting higher environmental behavioral intentions. Regarding willingness to volunteer for an environmental charity, the results showed an interaction effect between the type of care manipulation and the manipulation order. A further examination of this interaction term revealed a conditional effect of the type of care on volunteering. In particular, activating parental care positively influenced volunteering only when participants were presented with the children-cue manipulation first, $b=1.02, S E=0.45$, $p=0.02,95 \% \mathrm{CI}(0.14,1.90)$. However, when participants were presented with the type of care manipulation first, activating parental care had a negative effect on willingness to volunteer, $b=-1.16$, $S E=0.48, p=0.01,95 \%$ CI $(-2.10,-0.21)$.

\subsubsection{Exploratory Analyses of the Indirect Effect of Manipulated Parental Care Through Measured Parental Care}

Our pre-registered analysis plan involved only the moderated moderations described above. However, our data allow us to explore whether the indirect effects seen in Studies 1-3 also appear when parental care is manipulated directly (i.e., without any sustainability reference). To test this in an exploratory fashion, we tested the indirect effect of manipulated parental care on our three dependent variables.

The results were consistent with the previous studies. The type of care manipulation influenced measured parental care, $b=0.19, S E=0.07,95 \% \mathrm{CI}(0.06,0.32)$, and measured parental care in turn was positively associated with environmental behavioral intentions, $b=0.33, S E=0.06,95 \% \mathrm{CI}(0.21,0.46)$, but not with the percentage of donation, $b=1.72, S E=2.40,95 \% \mathrm{CI}(-3.02,6.45)$, nor with willingness to volunteer, $b=0.33, S E=0.32,95 \% \mathrm{CI}(-0.29,0.96)$. Also, the results showed a significant positive indirect effect through measured parental care on environmental behavioral intentions, $b=0.06, S E=$ $0.03,95 \% \mathrm{CI}(0.02,0.12)$, but not on percentage of donation, $b=0.32, S E=0.41,95 \% \mathrm{CI}(-0.36,1.24)$, or on volunteering, $b=0.06, S E=0.07,95 \% \mathrm{CI}(-0.05,0.24)$. Figure 4 presents further details. 
Table 1. Moderated moderation models of children-cue manipulation $(\mathrm{X})$, type of care manipulation (W), and manipulation order ( $\mathrm{Y})$ on environmental behavioral intentions and environmental altruistic intentions.

\begin{tabular}{|c|c|c|c|c|c|c|c|c|c|}
\hline \multirow[b]{2}{*}{ Predictors } & \multicolumn{3}{|c|}{$\begin{array}{l}\text { Environmental Behavioral } \\
\text { Intentions }\end{array}$} & \multicolumn{3}{|c|}{ Percentage of Donation } & \multicolumn{3}{|c|}{ Volunteering } \\
\hline & Estimate & SE & CI & Estimate & SE & $\mathrm{CI}$ & Estimate & SE & $\mathrm{CI}$ \\
\hline Children-cue & 0.01 & 0.07 & $-0.14,0.15$ & -2.07 & 2.63 & $-7.25,3.11$ & -0.06 & 0.35 & $-0.75,0.63$ \\
\hline Type of Care & 0.07 & 0.08 & $-0.08,0.22$ & -0.46 & 2.75 & $-5.87,4.95$ & -0.08 & 0.35 & $-0.77,0.61$ \\
\hline Manipulation Order & $-0.16^{*}$ & 0.07 & $-0.30,-0.02$ & -0.08 & 2.62 & $-5.24,5.09$ & -0.59 & 0.35 & $-1.27,0.09$ \\
\hline Children-Cue $\times$ Type of Care & -0.01 & 0.14 & $-0.30,0.27$ & 4.28 & 5.27 & $-6.09,14.65$ & -1.15 & 0.69 & $-0.19,2.50$ \\
\hline Children-Cue $\times$ Manipulation Order & 0.09 & 0.14 & $-0.19,0.37$ & 8.24 & 5.23 & $-2.05,18.53$ & -0.02 & 0.70 & $-1.38,1.35$ \\
\hline \multirow{3}{*}{$\begin{array}{c}\text { Type of Care } \times \text { Manipulation Order } \\
\text { Children-Cue } \times \text { Type of Care } \times \\
\text { Manipulation Order }\end{array}$} & -0.02 & 0.14 & $-0.30,0.27$ & -0.32 & 5.28 & $-10.71,10.08$ & $-2.22 *$ & 0.69 & $-3.57,-0.87$ \\
\hline & 0.47 & 0.29 & $-0.10,1.04$ & 12.08 & 10.55 & $-8.67,32.84$ & 1.43 & 1.38 & $-1.27,4.13$ \\
\hline & \multicolumn{3}{|c|}{$R^{2}=0.05, F(12,297)=1.22, p=0.27$} & \multicolumn{3}{|c|}{$R^{2}=0.05, F(12,297)=1.31, p=0.21$} & \multicolumn{3}{|c|}{$\begin{array}{c}-2 \mathrm{LL}=269.86, \text { Nagelkerke } R^{2}=0.17 \\
p<0.001\end{array}$} \\
\hline
\end{tabular}

Bootstrapping was fixed to 5000 re-samples and bias-corrected; ${ }^{*}=$ CIs do not include zero. Age, sex, parenthood status, and positive and negative emotions were statistically controlled in all the models. Children-cue: $0=$ control, $1=$ present; type of care: $0=$ friendship care, $1=$ parental care; Manipulation order: $0=$ children-cue manipulation presented first, $1=$ type of care manipulation presented first. 
Model 1

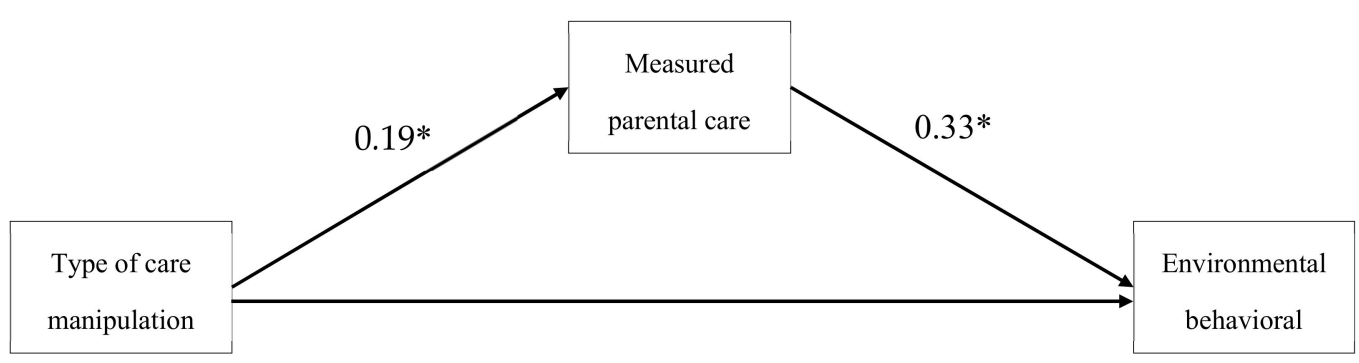

Full model: $F(7,302)=5.08, p<0.001, R^{2}=0.11$.

Model 2

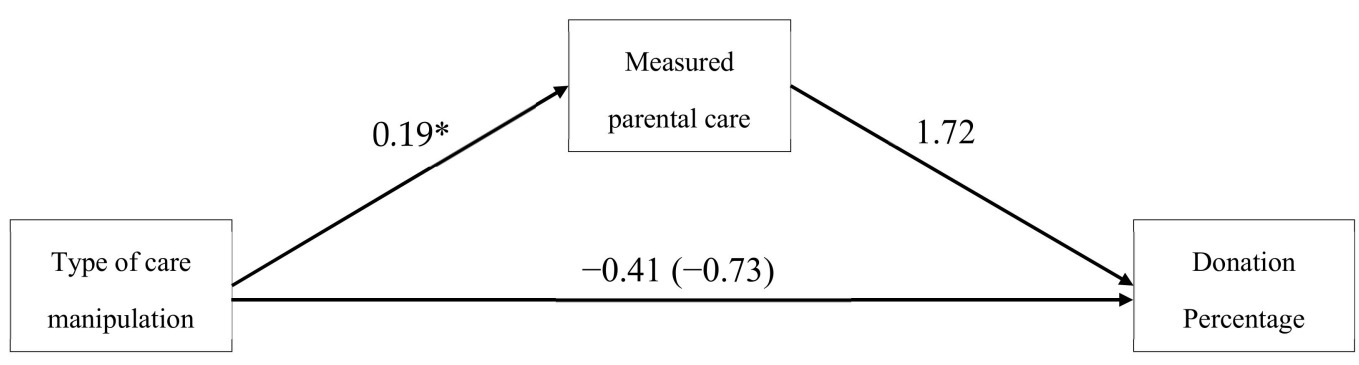

Full model: $F(7,302)=1.60, p=0.14, R^{2}=0.04$

Model 3

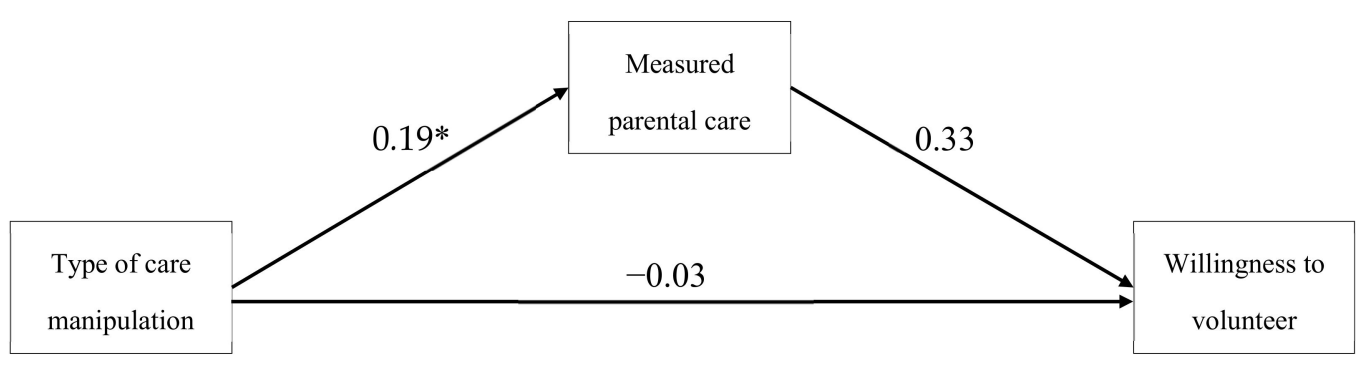

Logistic regression: $-2 \mathrm{LL}=287.56, p=0.02$, Nagelkerke $R^{2}=0.09$.

Figure 4. Effects of the type of care manipulation on environmental behavioral intentions and environmental altruistic intentions in Study 4. Bootstrapping was fixed to 5000 re-samples and bias-corrected. * = CIs do not include zero. Age, sex, parenthood status, and positive and negative emotions were statistically controlled in each model. Type of care manipulation: $0=$ friendship care, 1 $=$ parental care. Total effects in Model 1 and Model 2 are presented between parenthesis next to the direct ones.

\subsection{Discussion}

In Study 4, we applied a concurrent double randomization design to test the effects of parental care and children-cues separately [55]. The results did not support our predictions for the main effect of children-cues nor for its interaction with (manipulated) parental care on environmental outcomes. Instead, the results only showed an interactive effect between the type of care and the order of manipulations on volunteering. That is, when the manipulation of offspring cue was presented first, activating parental care increased the likelihood of volunteering. However, when the children-cue manipulation was presented after the type of care one, parental care tended to reduce volunteering. This result, though unexpected, seems to suggest that the effect of parental care on pro-environmental 
actions might only occur under certain circumstances. Despite the lack of main and interactive effects on the dependent variables, our results again showed the positive indirect effect of parental care on environmental behavioral intentions. Importantly, and different from the previous studies, in this study, the parental care motive was activated in isolation of sustainably references (e.g., parental care was not embedded within environmental messages or pictures). This suggests that the environmental benefits of activating parental care do not only arise when phrased within environmental-related contexts.

\section{Additional Analyses}

Across four studies, our findings show a stable positive indirect effect of children-based appeals on environmental behavioral intentions. In these studies, we focused on the unique effect of a cue of having children on environmental outcomes; therefore, we decided to statistically control for potentially influencing factors derived from the participants' life history such as sex, age, and parenthood status. Given that previous research has shown that parents have a higher parental care [36], one way to triangulate our findings was to evaluate the effect of actual parenthood status. To test this, we used the samples of Studies 1-4 to conduct a meta-analysis of the effects of parenthood status on environmental behavioral and altruistic measures. As the studies were not identical, we considered random effects to be an appropriate meta-analytic procedure. Fifteen correlation coefficients across the four studies were analyzed. Overall, compared to non-parents, parents showed greater environmental behavioral and altruistic intentions, $r=0.089$ (since this effect size was small, we tested whether it was equivalent to 0 [61]. Given the bounds $(-0.10,10)$ and $\alpha=0.05$, the TOSTmeta analysis showed that $d=0.191$ (i.e., $r$ $=0.089)$ was statistically different from zero and statistically not equivalent to $0(Z=5.29, p<0.001 ; Z$ $=1.65, p=0.951)$; thus, it cannot be considered trivial), $95 \%$ CI $(0.035,0.143)$, and the correlations were homogenous, $\chi^{2}(3)=1.605, p=0.658$. Moreover, $0 \%$ of the variance in effect-sizes can be explained by the differences among studies. This effect was not moderated by the type of outcome being predicted (i.e., environmental behavioral intentions, donations, and volunteering), $\chi^{2}(3)=1.624, p=0.654$.

Similarly, a second meta-analysis $(k=4)$ showed that parental care was positively associated with being a parent, $r=0.345,95 \% \mathrm{CI}(0.263,0.422)$, and correlations were not homogenous, $\chi^{2}(3)=8.294, p$ $=0.040$. Approximately $64 \%$ of the variance in effect-sizes could be explained by the differences among studies which is a relatively modest percentage.

\section{General Discussion}

Based on the kin selection perspective [15] and the fundamental motives framework [33], we hypothesized that an appeal to the welfare of one's children would stimulate pro-environmental intentions by tapping into a stronger parental care motivation [32,33]. Indeed, the results from four separate studies consistently supported this hypothesis, at least, regarding environmental behavioral intentions. These results are aligned with previous research indicating that people behave in an environmentally more sustainable way for inclusive fitness reasons-without them necessarily always being consciously aware of this deeper motivation $[21,26,28]$. Also, our meta-analytic exploration of the effect of parenthood status across the four studies helped to triangulate these findings.

Findings from environmental psychology and environmental demographics about the effect of having children on environmentalism have been somewhat inconclusive $[22,24,29,30]$. One possible explanation for this is that these lines of research have generally focused on the proximate causes of environmental behavior (i.e., parents trying to meet children's school-derived expectations regarding sustainable behavior at home; [62]). In our studies, we focused on a deeper evolutionary motivation: people might behave in sustainable ways to make sure their children - thus, their genetic future-will have a clean environment to live in [3].

Study 1 showed that a children-cue compared with a control condition indirectly increases environmental intentions through activating greater parental care. Study 2 replicated this finding. However, contrary to our prediction, own-children cues did not affect environmental intentions differently than a generic future generations cue. One potential explanation for this could be that there 
is some overlap between the cues as future generations also include your own biological offspring. This could be explained in terms of how humans' semantic networks operate. The network, a multilevel and multi-node structure, can be activated by external stimuli. However, a stimulus usually activates not just one node or one level but elicits cross-activation [63]. Nodes representing concepts (e.g., one's children and future generations) are connected, and the stronger the connection, the faster and more effective the activation of one concept by another [64]. Thus, thinking about future generations might activate concerns about one's (future) children and the other way around, because the concepts could be semantically related. A second potential explanation refers to the accuracy of the motivational system. It could be that the motivational system is not perfect in detecting the difference between a cue of one's own offspring and a cue of future generations.

Given that children act as connections with an abstract future [65,66], an alternative explanation of our overall findings could be that an appeal to the welfare of one's children, instead of activating parental care, reduces people's temporal discount rates. In order to evaluate this possible explanation, Study 3 was carried out. In particular, Study 3 tested whether an increased parental care motive (instead of a reduced discounting rate) was indeed the mechanism that drove the effects seen in Studies 1 and 2.

The findings of Study 3 were consistent with kin selection theory, at least in terms of predicting greater environmental behavioral intentions. The children cue positively affected environmental behavioral intentions by increasing one's parental care motivation. More importantly, the cue of having children did not reduce participants' discount rates nor did it show any indirect effect on environmental behavioral and altruistic intentions through reduced discounting. Thus, it seems likely that each positive indirect effect of the children-based appeal over the environmental behavioral intentions was being driven by parental care. In addition, Study 3 also replicated previous research on time delays in environmental information, indicating that phrasing environmental consequences as being sooner (rather than delayed in time) strengthens people's environmental intentions [47]. Indeed, this result is consistent with the psychological distance literature indicating that the closer people perceive environmental threats, the more they tend to engage in mitigating actions [67].

The results of Studies 1-4 consistently showed a positive indirect effect of children-cues (and manipulated parental care in Study 4) on environmental behavioral intentions through increased parental care motivation. But what about the direct effect of offspring cues on environmental outcomes? Although previous findings on this matter have been rather mixed (e.g., [26,30]), in Study 4, we tested the effect of a children-cue and parental care independently. Our results did not provide support for a unique direct effect of the children-cue on environmental behavioral intentions nor on environmental altruistic intentions. The lack of children-cue/kin-care manipulation priming effects could be explained in terms of weak effects of priming on intentions and behavior overall (for a review see Reference [68]; e.g., [69-71]) and the weak impact of automatic system activated by a prime on intentions and behavior; if some conditions are not met, for example, cognitive resources are not tapped [72,73] or the priming is not sufficiently contextualized to activate certain reactions [74]. Thus, only if the children-cue priming was sufficiently increasing parental care, then could we observe a slight change in environmental intentions, indicating the indirect effect. In other words, increased parental care created adequate conditions for reactions guided by the priming [75]. Alternatively, the indirect-only effects [35] seen in our studies might be due to the presence of a competing mediator that has yet to be unveiled. Such a competing mechanism should be positively influenced by child-cues but negatively related pro-environmental intentions thus canceling out a potential direct effect of child-cues on the dependent variables (e.g., inconsistent mediation [76]). Although there might be multiple constructs that match these relationship patterns, as previously suggested by some authors [26,30], two likely candidates are financial concerns and time constraints. Raising a newborn is usually associated with more expenses and less free time in a household. Then, as resources and time are being diverted into the new family member, relatively expensive and time-consuming pro-environmental lifestyles are not likely to be adopted. Future work should explore these ideas further. 
Despite the lack of direct effects, however, Study 4 allowed us to explore whether the sustainability benefits of parental care are confined to manipulations in which this motive is activated within an environmental context (i.e., embedded in environmental messages). The results do not seem to suggest this. Instead, the results replicated the positive indirect effect of parental care on environmental behavioral intentions we observed in the previous studies. This result seems worth noting, as it suggests that policymakers could activate parental care in a variety of ways (and indirectly foster pro-environmental behavior) and not only by environmental messaging. Such versatility could probably enable the use of parental care motivation for sustainability purposes in a wider range of public policy campaigns.

Regarding the environmental altruistic intentions, findings across the four studies were less consistent. In particular, even though Study 1 showed the expected positive indirect effect of children-based appeals on environmental altruistic intentions, Studies $2-4$ did not yield a similar effect. It could be that environmental altruistic intentions (e.g., donating, volunteering) are not perceived as directly affecting one's children's local environment and, thus, cannot be guided directly or indirectly by priming with children-cues. Instead, visible altruistic intentions might be more influenced by reputational concerns instead of parental care motivation. Developing a good reputation by means of altruistic displays tend to increase individuals' overall fitness through indirect reciprocity [77]. Indeed, in resource dilemmas, people tend to contribute more to the common pool when they believe that such contribution will improve their reputation [78].

\subsection{Limitations and Future Directions}

Our research is not exempt from limitations. First, the present studies only focused on the indirect effects of children-cues on environmental behavioral and altruistic intentions. We did not explore whether cues of other genetically related relatives (e.g., siblings, grandchildren) also increase environmental intentions as kin selection theory holds. Future studies should build upon our results, investigating, for instance, whether grandchildren's cues would produce the same results. Second, although our studies contained outcome measures that allow the exploration of a wide range of environmental intentions, many of them - but certainly not all-were fairly low-cost activities, making conclusions about the effects of children cues on high-cost intentions difficult to make. Similarly, participants were not requested to engage in actual environmental behavior, having to report their intentions only. Future research could fill this gap by testing the effect of the parental care motive on environmental activities that require bigger personal sacrifices as well as on actual behavior. Finally, our children cue did not indirectly lead to more pro-environmental intentions when compared to the generic future-generations cue in Study 2. We proposed that the overlap between the two cues could be the reason for the lack of difference, and future studies could test that hypothesis. For instance, a lexical decision task (LDT) could be applied [79]. In such a task, reaction times towards presented categories are used to identify differences/similarities in semantic network activation [64]. If a future generation cue activates the same nodes as offspring cue reaction times in an LDT should be similar. Thus, in order to study that further, a distinction between genetically similar future-generations and genetically non-similar future-generations categories could be tested.

\subsection{Conclusions}

Going back to the question raised at the beginning of this paper: are governments and the people who vote for them persuaded by appeals about the welfare of their children and grandchildren? Our results indicated that they are, though through an indirect evolutionary-rooted motivation: parental care. In particular, in the current research, we tested whether the care for children, an evolutionary relevant motive derived from kin selection, would be associated with people's environmental intentions. Overall, the findings indicate that activating the parental care motive indirectly increases people's environmental intentions. Our findings may have some practical implications. Environmental policymakers could convey environmental messages that accentuate the genetic interests of citizens more strongly (e.g., 
an appeal to Mother Nature; [10]) but also messages stressing genetic interests that do not mention sustainability references (as seen in Study 4). Importantly, this does not imply that policymakers should encourage individuals to become parents sooner or have more children, considering the relatively large negative environmental consequences associated with larger populations [80]. Instead of focusing on the fate of our planet, environmental policymakers could create child-based messages which will indirectly lead people to reflect on the negative consequences of environmental (in)actions and engage in more pro-environmental behaviors.

Supplementary Materials: The following are available online at http://www.mdpi.com/2071-1050/12/2/748/s1, Figure S1: Effects of the children-cue manipulation on environmental behavioral intentions and environmental altruistic intentions in Study 1 without statistical controls. Figure S2: Effects of the own-child cue manipulation on environmental behavioral intentions and environmental altruistic intentions in Study 2 without statistical controls. Figure S3: Effects of the children-cue manipulation on environmental behavioral intentions and environmental altruistic intentions in Study 3 without statistical controls. Figure S4: Effects of the type of care manipulation on environmental behavioral intentions and environmental altruistic intentions in Study 4 without statistical controls. Table S1: Moderated moderation modes of offspring cue manipulation (X), type of care manipulation (W), and manipulation order $(Y)$ on environmental behavioral intentions and environmental altruistic intentions in Study 4 without statistical controls. Along with these figures and table, experimental materials and verbatim measures can also be found in the supplementary materials.

Author Contributions: All authors have read and agreed to the published version of the manuscript.

Funding: This work was supported by the Advanced Human Capital Program of the Chilean National Commission for Scientific and Technological Research (Doctorado Becas Chile/2015 - 72160020).

Conflicts of Interest: The authors declare no conflict of interest.

Ethical Approval: All the studies presented in this paper were conducted after approval by the Scientific and Ethical Review Board of the Faculty of Behavioural and Movement Sciences of the Vrije Universiteit Amsterdam (reference number: VCWE-2016-150).

\section{References}

1. IPCC. Summary for Policymakers. In Global Warming of $1.5^{\circ} \mathrm{C}$. An IPCC Special Report on the Impacts of Global Warming of $1.5^{\circ} \mathrm{C}$ Above Pre-Industrial Levels and Related Global Greenhouse Gas Emission Pathways, in the Context of Strengthening the Global Response to the Threat of Climate Change, Sustainable Development, and Efforts to Eradicate Poverty; Masson-Delmotte, V., Zhai, H.-O., Pörtner, D., Skea, P., Shukla, A., Pirani, W., Moufouma-Okia, C., Péan, R., Pidcock, S., Connors, J., et al., Eds.; IPCC: Geneva, Switzerland, 2018.

2. Barclay, E.; Resnick, B. How big was the global climate strike? 4 million people, activists estimate. Vox, 22 September 2019.

3. Griskevicius, V.; Cantú, S.; Van Vugt, M. The Evolutionary Bases for Sustainable Behavior: Implications for Marketing, Policy, and Social Entrepreneurship. J. Public Policy Mark. 2012, 31, 115-128. [CrossRef]

4. Van Lange, P.; Balliet, D.; Parks, C.; Van Vugt, M. Social Dilemmas: Understanding Human Cooperation; Oxford University Press: Oxford, UK, 2013.

5. Joireman, J. Environmental problems as social dilemmas: The temporal dimension. In Understanding Behavior in the Context of Time: Theory, Research, and Application; Strathman, A., Joireman, J., Eds.; Lawrence Erlbaum: Mahwah, NJ, USA, 2015; pp. 289-304.

6. Van Lange, P.; Joireman, J.; Parks, C.; Van Dijk, E. The psychology of social dilemmas: A review. Organ. Behav. Hum. Decis. Process. 2013, 120, 125-141. [CrossRef]

7. Shankar, A.; Pavitt, C. Resource and public goods dilemmas: A new issue for communication research. Rev. Commun. 2002, 2, 251-272.

8. Hardin, G. The tragedy of the commons. Science 1968, 162, 1243-1248. [PubMed]

9. Hamilton, W. The genetical evolution of social behaviour. I. J. Theor. Biol. 1964, 7, 1-16. [CrossRef]

10. Van Vugt, M.; Griskevicius, V.; Schultz, P. Naturally Green: Harnessing Stone Age Psychological Biases to Foster Environmental Behavior. Soc. Issues Policy Rev. 2014, 8, 1-32. [CrossRef]

11. Bravo, G.; Squazzoni, F. Exit, punishment and rewards in commons dilemmas: An experimental study. PLoS ONE 2013, 8, e69871. [CrossRef]

12. Srinivasan, S. Inducing pro-environmental behaviour: Moral suasion, reciprocal altruism and the Man-in-the-Middle. Int. J. Green Econ. 2012, 6, 37-54. [CrossRef] 
13. Griskevicius, V.; Tybur, J.; Van den Bergh, B. Going green to be seen: Status, reputation, and conspicuous conservation. J. Personal. Soc. Psychol. 2010, 98, 392-404. [CrossRef]

14. Van Vugt, M.; Iredale, W. Men behaving nicely: Public goods as peacock tails. Br. J. Psychol. 2013, 104, 3-13. [CrossRef]

15. Park, J.; Schaller, M.; Van Vugt, M. Psychology of human kin recognition: Heuristic cues, erroneous inferences, and their implications. Rev. Gen. Psychol. 2008, 12, 215. [CrossRef]

16. Mitani, J.; Merriwether, D.; Zhang, C. Male affiliation, cooperation and kinship in wild chimpanzees. Anim. Behav. 2000, 59, 885-893. [CrossRef] [PubMed]

17. Parsons, K.; Durban, J.; Claridge, D.; Balcomb, K.; Noble, L.; Thompson, P. Kinship as a basis for alliance formation between male bottlenose dolphins, Tursiops truncatus, in the Bahamas. Anim. Behav. 2003, 66, 185-194. [CrossRef]

18. Foster, K. Diminishing returns in social evolution: The not-so-tragic commons. J. Evol. Biol. 2004, 17, 1058-1072. [CrossRef] [PubMed]

19. West, S.; Griffin, A.; Gardner, A. Social semantics: Altruism, cooperation, mutualism, strong reciprocity and group selection. J. Evol. Biol. 2007, 20, 415-432. [CrossRef] [PubMed]

20. Burnstein, E.; Crandall, C.; Kitayama, S. Some neo-Darwinian decision rules for altruism: Weighing cues for inclusive fitness as a function of the biological importance of the decision. J. Personal. Soc. Psychol. 1994, 67, 773-789. [CrossRef]

21. Krupp, D.; Debruine, L.; Barclay, P. A cue of kinship promotes cooperation for the public good. Evol. Hum. Behav. 2008, 29, 49-55. [CrossRef]

22. Grunert, S. Everybody seems concerned about the environment: But is this concern reflected in (Danish) consumers' food choice? In European Advances in Consumer Research; Bamossy, G.J., Fred van Raaij, W., Eds.; Association for Consumer Research: Provo, UT, USA, 1993; Volume 1, pp. 428-433.

23. Dupont, D. Do children matter? An examination of gender differences in environmental valuation. Ecol. Econ. 2004, 49, 273-286. [CrossRef]

24. Laroche, M.; Bergeron, J.; Barbaro-Forleo, G. Targeting consumers who are willing to pay more for environmentally friendly products. J. Consum. Mark. 2001, 18, 503-520. [CrossRef]

25. Loureiro, M.; McCluskey, J.; Mittelhammer, R. Will consumers pay a premium for eco-labeled apples? J. Consum. Aff. 2002, 36, 203-219. [CrossRef]

26. Van de Vyver, J.; Abrams, D.; Hopthrow, T.; Purewal, K.; de Moura, G.; Meleady, R. Motivating the selfish to stop idling: Self-interest cues can improve environmentally relevant driver behaviour. Transp. Res. Part $F$ Traffic Psychol. Behav. 2018, 54, 79-85. [CrossRef]

27. Morris, D.; Qirko, H. Saving "Little Sister": A Test of the Effectiveness of Kinship Appeals on Conservation Marketing. Environ. Commun. 2019. [CrossRef]

28. Neufeld, S.; Griskevicius, V.; Ledlow, S.; Li, Y.J.; Neel, R.; Berlin, A.; Yee, C. Going green to Help your genes: Kin-based appeals in environmental messaging. In Proceedings of the Sustainability Psychology Preconference of the Annual Meeting of the Society for Personality and Social Psychology, San Diego, CA, USA, 26-28 January 2012.

29. Fisher, C.; Bashyal, S.; Bachman, B. Demographic impacts on environmentally friendly purchase behaviors. J. Target. Meas. Anal. Mark. 2012, 20, 172-184. [CrossRef]

30. Thomas, G.; Fisher, R.; Whitmarsh, L.; Milfont, T.; Poortinga, W. The impact of parenthood on environmental attitudes and behaviour: A longitudinal investigation of the legacy hypothesis. Popul. Environ. 2018, 39, 261-276. [CrossRef]

31. Ekholm, S.; Olofsson, A. Parenthood and Worrying About Climate Change: The Limitations of Previous Approaches. Risk Anal. 2017, 37, 305-314. [CrossRef]

32. Griskevicius, V.; Kenrick, D. Fundamental motives: How evolutionary needs influence consumer behavior. J. Consum. Psychol. 2013, 23, 372-386. [CrossRef]

33. Kenrick, D.; Griskevicius, V.; Neuberg, S.; Schaller, M. Renovating the pyramid of needs contemporary extensions built upon ancient foundations. Perspect. Psychol. Sci. 2010, 5, 292-314. [CrossRef]

34. Brown, N.; Neel, R.; Sherman, R. Measuring the evolutionarily important goals of situations: Situational affordances for adaptive problems. Evol. Psychol. 2015, 13, 1-15. [CrossRef]

35. Zhao, X.; Lynch, J.; Chen, Q. Reconsidering Baron and Kenny: Myths and Truths about Mediation Analysis. J. Consumer Res. 2010, 37, 197-206. [CrossRef] 
36. Neel, R.; Kenrick, D.; White, A.; Neuberg, S. Individual differences in fundamental social motives. J. Personal. Soc. Psychol. 2016, 110, 887-907. [CrossRef]

37. Kenny, D.; Kashy, D.; Bolger, N. Data analysis in social psychology. In The Handbook of Social Psychology; Gilbert, D., Fiske, S., Lindzey, G., Eds.; McGraw-Hill: Boston, MA, USA, 1998.

38. Preacher, K.; Hayes, A. Asymptotic and resampling strategies for assessing and comparing indirect effects in multiple mediator models. Behav. Res. Methods 2008, 40, 879-891. [CrossRef] [PubMed]

39. Shrout, P.; Bolger, N. Mediation in experimental and nonexperimental studies: New procedures and recommendations. Psychol. Methods 2002, 7, 422-445. [CrossRef] [PubMed]

40. Fritz, M.; MacKinnon, D. Required sample size to detect the mediated effect. Psychol. Sci. 2007, 18, $233-239$. [CrossRef] [PubMed]

41. Kaiser, F. A General Measure of Ecological Behavior. J. Appl. Soc. Psychol. 1998, 28, 395-422. [CrossRef]

42. Hayes, A. Introduction to Mediation, Moderation, and Conditional Process Analysis: A Regression-Based Approach, 2nd ed.; The Guilford Press: New York, NY, USA, 2018.

43. Hayes, A.; Preacher, K. Statistical mediation analysis with a multicategorical independent variable. Br. J. Math. Stat. Psychol. 2014, 67, 451-470. [CrossRef] [PubMed]

44. Frederick, S.; Loewenstein, G.; O’Donoghue, T. Time Discounting and Time Preference: A Critical Review. J. Econ. Lit. 2002, 40, 351-401. [CrossRef]

45. Daly, M.; Wilson, M. Carpe diem: Adaptation and devaluing the future. Q. Rev. Biol. 2005, 80, 55-60. [CrossRef]

46. Green, L.; Myerson, J. A discounting framework for choice with delayed and probabilistic rewards. Psychol. Bull. 2004, 130, 769-792. [CrossRef]

47. Kortenkamp, K.; Moore, C. Time, uncertainty, and individual differences in decisions to cooperate in resource dilemmas. Personal. Soc. Psychol. Bull. 2006, 32, 603-615. [CrossRef]

48. Wade-Benzoni, K. A golden rule over time: Reciprocity in intergenerational allocation decisions. Acad. Manag. J. 2002, 45, 1011-1028. [CrossRef]

49. Ellis, B.; Figueredo, A.; Brumbach, B.; Schlomer, G. Fundamental Dimensions of Environmental Risk: The Impact of Harsh versus Unpredictable Environments on the Evolution and Development of Life History Strategies. Hum. Nat. 2009, 20, 204-268. [CrossRef] [PubMed]

50. Van Gelder, J.; Hershfield, H.; Nordgren, L. Vividness of the future self predicts delinquency. Psychol. Sci. 2013, 24, 974-980. [CrossRef] [PubMed]

51. Griskevicius, V.; Ackerman, J.M.; Cantú, S.M.; Delton, A.W.; Robertson, T.E.; Simpson, J.A.; Thompson, M.E.; Tybur, J.M. When the Economy Falters, Do People Spend or Save? Responses to Resource Scarcity Depend on Childhood Environments. Psychol. Sci. 2013, 24, 197-205. [CrossRef] [PubMed]

52. Wu, J.; Balliet, D.; Tybur, J.M.; Arai, S.; Van Lange, P.A.M.; Yamagishi, T. Life history strategy and human cooperation in economic games. Evol. Hum. Behav. 2017, 38, 496-505. [CrossRef]

53. Griskevicius, V.; Tybur, J.M.; Ackerman, J.M.; Delton, A.W.; Robertson, T.E.; White, A.E. The financial consequences of too many men: Sex ratio effects on saving, borrowing, and spending. J. Personal. Soc. Psychol. 2012, 102, 69-80. [CrossRef]

54. Kirby, K.; Petry, N.; Bickel, W. Heroin and cocaine abusers have higher discount rates for delayed rewards than alcoholics or non-drug-using controls. Addiction 2004, 99, 461-471. [CrossRef]

55. Pirlott, A.; MacKinnon, D. Design approaches to experimental mediation. J. Exp. Soc. Psychol. 2016, 66, 29-38. [CrossRef]

56. Perugini, M.; Gallucci, M.; Costantini, G. A practical primer to Power analysis for simple experimental designs. Int. Rev. Soc. Psychol. 2018, 31. [CrossRef]

57. Goodman, J.; Cryder, C.; Cheema, A. Data Collection in a Flat World: The Strengths and Weaknesses of Mechanical Turk Samples. J. Behav. Decis. Mak. 2013, 26, 213-224. [CrossRef]

58. Pennebaker, J.; Booth, R.; Boyd, R.; Francis, M. Linguistic Inquiry and Word Count: LIWC2015.; Pennebaker Conglomerates: Austin, TX, USA, 2015.

59. Li, Y.; Haws, K.; Griskevicius, V. Parenting motivation and consumer decision-making. J. Consum. Res. 2018, 45, 1117-1137. [CrossRef]

60. Ma, D.; Correll, J.; Wittenbrink, B. The Chicago face database: A free stimulus set of faces and norming data. Behav. Res. Methods 2015, 47, 1122-1135. [CrossRef] [PubMed] 
61. Lakens, D.; Scheel, A.; Isager, P. Equivalence testing for psychological research: A tutorial. Adv. Methods Pract. Psychol. Sci. 2018, 1, 259-269. [CrossRef]

62. Brooker, G. The Self-Actualizing Socially Conscious Consumer. J. Consum. Res. 1976, 3, 107-112. [CrossRef]

63. Collins, A.; Quillian, M. How to make a language user. In Organization of Memory; Tulving, E., Donaldson, W., Eds.; Academic Press: New York, NY, USA, 1972; pp. 309-351.

64. Collins, A.; Loftus, E. A spreading-activation theory of semantic processing. Psychol. Rev. 1975, 82, 407-428. [CrossRef]

65. Shirani, F.; Butler, C.; Henwood, K.; Parkhill, K.; Pidgeon, N. Disconnected futures: Exploring notions of ethical responsibility in energy practices. Local Environ. 2013, 18, 455-468. [CrossRef]

66. Shirani, F.; Groves, C.; Butler, C.; Parkhill, K.; Henwood, K.; Pidgeon, N. Living in the future: Environmental concerns, parenting, and low-impact lifestyles. In Geographies of Global Issues: Change and Threat, Geographies of Children and Young People; Ansell, N., Klocker, N., Skelton, T., Eds.; Springer: Singapore, 2015; Volume 8, pp. 1-20.

67. Rickard, L.; Yang, Z.; Schuldt, J. Here and now, there and then: How "departure dates" influence climate change engagement. Glob. Environ. Chang. 2016, 38, 97-107. [CrossRef]

68. Cesario, J. Priming, replication, and the hardest science. Perspect. Psychol. Sci. 2014, 8, 40-48. [CrossRef]

69. Doyen, S.; Klein, O.; Pichon, C.; Cleeremans, A. Behavioral priming: It's all in the mind, but whose mind? PLOS ONE 2012, 7. [CrossRef]

70. Harris, C.; Coburn, N.; Rohrer, D.; Pashler, H. Two failures to replicate high-performance-goal priming effects. PLoS ONE 2013, 8, e72467. [CrossRef]

71. Pashler, H.; Rohrer, D.; Harris, C. Can the goal of honesty be primed? J. Exp. Soc. Psychol. 2013, 49, 959-964. [CrossRef]

72. Hofmann, W.; Friese, M.; Strack, F. Impulse and self-control from a dual-systems perspective. Perspect. Psychol. Sci. 2009, 4, 162-176. [CrossRef] [PubMed]

73. Strack, F.; Deutsch, R. Reflective and impulsive determinants of social behavior. Personal. Soc. Psychol. Rev. Off. J. Soc. Personal. Soc. Psychol. 2004, 8, 220-247. [CrossRef] [PubMed]

74. Barsalou, L. Situated conceptualization offers a theoretical account of social priming. Curr. Opin. Psychol. 2016, 12, 6-11. [CrossRef]

75. Krpan, D. Behavioral priming 2.0: Enter a dynamical systems perspective. Front. Psychol. 2017, 8. [CrossRef]

76. MacKinnon, D.P.; Krull, J.L.; Lockwood, C.M. Equivalence of the Mediation, Confounding and Suppression Effect. Prev. Sci. 2000, 1, 173-181. [CrossRef]

77. Nowak, M.; Sigmund, K. Evolution of indirect reciprocity. Nature 2005, 1291-1298. [CrossRef]

78. Barclay, P. Trustworthiness and competitive altruism can also solve the "tragedy of the commons". Evol. Hum. Behav. 2004, 25, 209-220. [CrossRef]

79. Martijn, C.; Alberts, H.; Merckelbach, H.; Havermans, R.; Huijts, A.; De Vries, N. Overcoming ego-depletion: The influence of exemplar priming on self-control performance. Eur. J. Soc. Psychol. 2007, 37, 231-238. [CrossRef]

80. Wynes, S.; Nicholas, K. The climate mitigation gap: Education and government recommendations miss the most effective individual actions. Environ. Res. Lett. 2017, 12, 074024. [CrossRef]

(C) 2020 by the authors. Licensee MDPI, Basel, Switzerland. This article is an open access article distributed under the terms and conditions of the Creative Commons Attribution (CC BY) license (http://creativecommons.org/licenses/by/4.0/). 